\title{
Social Work Education in India and Australia
}

\author{
Rajendra Baikady ${ }^{1, *}$, Venkat Pulla ${ }^{2}$, Channaveer R.M ${ }^{1}$ \\ ${ }^{1}$ Department of Social Work, Central University of Karnataka, Gulbarga, India \\ ${ }^{2}$ Social Work Discipline, Australia Catholic University, Brisbane, Australia \\ *Corresponding Author: rajendrabaikady@yahoo.com
}

\begin{abstract}
This study attempts to cross-compare social work education, curriculum, research, fieldwork, and professional social work practices across India and Australia. It reviews the development of social work education along with its best practices in both these countries. In doing so, it aims to understand the policies related to social work and social welfare in both the countries. In India, the social work training began in the year 1936 whereas in Australia, it started in 1940 with its launch in the University of Sydney. In Australia, the professional association called Australian Association for Social Work (AASW) accredits course work authority while in India it is the University Grants Commission (UGC) and the National Accreditation and Assessment Council (NAAC). Social work education in Australian universities is generic and its aim is to produce graduates with a broad range of skills in a considerable range of practice settings. India offers both generic and specialised course works. Interestingly, to date, social work in none of the countries has a registration in compliance with any state or federal agency. However, self-regulation alongside continued professional development, and peer supervisions are encouraged and followed. In Australia, the practice standards are maintained by the Australian Social Work Education and Accreditation Standards (ASWEAS) who also regulate and guide curriculum development for social work programs in Australia. Fieldwork placement of social and community work students are dependent on the voluntary good will of the managers of social service agencies to support and resource.
\end{abstract}

Keywords Social Work Education, Best practices, Social work Policy, Globalization

\section{Background of Social Work Education}

Social Work is a discipline that grew out of humanitarian and democratic ideals and its values are based on equality, worth, and dignity of all the people in the society (www.ifsw.org). Human rights and the social justices are the main motivations behind the social action. Social work profession strives to alleviate poverty and uplift the vulnerable and oppressed people in the society in order to achieve the social inclusion and development. Therefore, the profession works in line to developing the full potential of the people or the communities, enriching their lives and thereby, aims to prevent the dysfunction. It incorporates and uses other social sciences as a means to improve the human condition and positively change society's response to chronic problems like poverty, unemployment, underemployment, child prostitution, malnutrition, health problems, human trafficking, discrimination, terrarium, etc. Thus, it seeks to address and resolve social issues at every level of society and economic status, but especially among the poor and the sick. Social workers are concerned with social problems, their causes, their solutions and their human impacts. They work with individuals, families, groups and communities.

Social work education exists within the national education systems of all the country, but the content, the pedagogy, and the practice may differ from one country to another. Until today, there is no universal pattern of education for the social workers. The new set of Global Standards for the Education and Training of the Social Work Profession (2004) developed by the International Association for School of Social Work in consultation with the International Federation for Social Workers, the two prominent organisations in the field of social work provides guidelines for social work education and its practices all over the world. This paper aims to speak about the social work education in India and in Australia, which are the two prominent countries in the Asia and the Pacific region of the world; hence, an attempt has been made to understand these two countries within a vast region with 49 nations covering a landmass of 17.2 million square miles. The Asian and Pacific Association for Social Work Education currently have 78-member institutions. In many Asian countries, social work education is generally at the undergraduate levels. As per Asia Pacific Association for Social Work education, China has more than 100 universities and colleges which are offering social work training, and continues to witness the most rapid growth of social work education, while Vietnam has recently started three schools of social work, Japan alone has 143 undergraduate schools and 81 graduate social work programs. Malaysia currently has five schools of social work, and the countries like Australia, Japan, India, Singapore, and the Philippines have had social work education for many years 
and have developed high standards for graduate social work education.

In India, the social work education has completed more than seven decades. As a discipline of study in the university department and affiliated, private, government colleges and deemed universities, social work has established its own mark.

Social work as a profession in Australia developed later than the UK or the America with the first professional social workers being hired in the 1920s (Camilleri, 2005) from USA. Social work training began in Australia in 1940 at the University of Sydney. The profession took direction from the established schools in England until the 1960s, when a more American model took hold. Most high-level training and theory was imported from abroad until the 1980s. Some Australian social work writers such as Jim Ife have criticised the impact that this has had on Australians being able to develop culturally appropriate theories and practices (Camilleri, 2005). Since the 1990s, Australian social work has increasingly affiliated itself with Pacific Islander and New Zealand approaches.

Social work has been a mostly public sector or not-for-profit sector profession in Australia, with private practices being rare. The profession has experienced changes in two different directions in the last 30 years. One is a pull towards a more managerial, professionalised model, and the other is to a more community based, de-professionalised approach. This has also been the trend by large organisations to replace the "jack of all trades" social work approach with less highly trained, more technical positions. Besides, since the 1990s, other reactions to managerial control of social work have followed theories of feminism, ecological sustainability and critical theories.

Historically, Australia has evolved a unique welfare system but with welfare reforms since the late 1990s, it increasingly bears the hallmarks of policy development, similar to that of the USA and the UK. For the most part, however, even in the face of economic globalisation, welfare policy remains the province of nation states, albeit influenced by international conventions and human rights charters. Claims that globalised capitalism has reduced the nation state's control of its territorial boundaries are overzealous. As noted by Hardy [2007cited in Mel Gray, 2011, p3], global capitalism 'has not necessitated the downfall of the nation-state for the reason that global culture fails to adequately decanter the ethno nationalist identity that citizens of a nation-state feel within their local community'. Instead, the nation state has become more open to multilateral transactions and accustomed to engaging with other nations and cultures (Gray, 2011).

Social work profession in Australia adheres to the definition of social work jointly agreed to by the International Federation of Social Workers and the International Association of School of Social Work in 2001.

\section{Structure and Content of Social Work: India}

In India, the structure of social work education in Bachelor (BSW) and Master's Degree (MSW, MA) is credit based semester system in many university departments and schools of social work across the country. The BSW is the first professional degree in social work in India, the main objective of the BSW degree is to equip the social work professionals with a generalist practice with individual, families, groups, organisations, and communities, while the Masters level social works objective is to prepare the graduates for the advanced practice in the areas concerned and to develop expertise in the optional fields. The minimum requirement for a professional position in this field is a bachelor's degree (B.S.W. or B.A). Bachelor's degree in social work is a three-year course open for all those who have passed their Pre- University education or its equivalent qualification. A graduate in any discipline can join for the Master's Degree course in Social work (M.S.W. / M.A) which is of two year duration. The admission to the MSW/MA in social work degree is open to all aspirants irrespective of that possess a bachelor's degree. Many universities in the country held an entrance examination at the national level to select the students. However, very few schools of social work follow three steps of selection process: National level written entrance examination, group discussions and, personal interactions. The content and the curriculum of the social work education (both bachelors and masters level) differs greatly from one institution to the other, while there are no single guidelines framing social work curriculum and the field-work component. On an average, the social work degree at the bachelor's level carries a maximum of 80 credits across theory and the practice components. Some of the schools follow three days of theory class and three days of practice in the bachelor's degree level, while some others follow two days of practice. There are no block placements components of a month long work in an agency or community or the department of the government or a hospital in the bachelor's degree level but there is a provision for the study tour with supervised instruction by the faculty. At the Masters' level, the social work curriculum does differ from institution to institution and the specialisations offered by the schools are also of different. The Master's course in social work bear 80-90 credits of requirement spread across four semesters. Out of the total number of credits, one third is reserved for the fieldwork practicum. Once again there is a variation in the specialisations provided across the schools in India. Many schools of social work and institutions provide the three basic specialisations like Human Resource and Personnel Management, Community Development/ Social Development and Medical and Psychiatric social work. The Masters level course has the provision for the block 
placement components as compulsory requirements in some schools of social work while an optional in other schools. Employment opportunities for social workers in India remain limited in the government sectors as such most social workers are employed in Non- governmental sectors. While roles may demand social work background a number of jobs do not specify any preference to social work qualification in job advertisements.

\section{Australia}

In Australia, BSW is of four years and it is the basic requirement for entry into the occupation of social worker. Some universities also offer a two-year, accelerated graduate-entry BSW. All the course are recognised by the Australian Association of Social Workers (AASW) and are deemed eligible for membership of the AASW. In Australia, there is no registration requirement for the social workers. Most of the employers in Australian society expect the prospect employees to be eligible to become a member of the AASW; the membership eligibility is given to only the graduates of courses recognised by the AASW. However, AASW membership is not compulsory and only a third of the social workers in the country are members. Australian entry-level professional social work education is generalist in nature with focus on core and common knowledge, skills and values, which can be applied across practice settings, fields of practice and methods of social work practice. An Australian professional social work program combines attributes of thinking, being and doing. It prepares graduates to be self-initiating, critically reflective, innovative and able to solve problems across a wide range of issues and situations, and in a diverse range of contexts. These attributes are informed by core values, including social justice, human rights, human dignity and equity. The social work discipline in Australia follows the contemporary pedagogical knowledge and the associated processes of learning that are required for developing core attributes and for building students 'commitment to, and an identity with, professional social work'.(AASW 2010, p 6) It is recognised that tensions exist between learning processes and requirements for content, and that there is a point at which the amount of content will compromise the processes of learning and the development of social work graduates as critically reflective professional practitioners. These standards strive for the appropriate balance. The content delivered in professional social work education is based on the principles of profession which encourages and supports students "commitment to and demonstration of the values and ideals of the social work profession as embraced by the AASW and defined by its 2010 constitution' (AASW 2010b, p. 1). These values and ideals derive from the profession's commitment to the pursuit of social justice, the enhancement of the quality of life and to maximising the development of the potential of each individual, family, group and community in society. Both content and delivery in Australian social work education will demonstrate the profession's core values: respect for persons, social justice and professional integrity as defined in the AASW Code of Ethics (2010a). Australian social work education recognises that social work operates at the interface between people and their social, cultural, spiritual and physical environments. Field education is a core component of the Australian entry-level professional social work education. It is a cooperative endeavor between the higher education provider, the student, agencies and field educators to assist the integration of theory and practice. In Australia, universities rely on practitioners' commitment to the profession for the provision of practice teaching, in most places voluntarily. Partnerships have the capacity to make this commitment worthwhile through strengthening the research capacity of practitioners and bringing current realities into the classroom. As noted above, there are views in Australian social work education that would marginalise field education. The focus of the ASWEAS is on outcomes and graduate attributes, the AASW requires that the following specific curriculum content be included in all social work programs:

- Mental health

- Child wellbeing and protection

- Cross-cultural practice

- $\quad$ Practice with Aboriginal and Torres Strait Islander peoples and communities

In addition to this, all social work program content should be taught in ways, which provide students with tools to be social workers within the definition provided in the introduction to these standards. While Australian social work follows the IASSW practice standards for the fieldwork practice, which says: in fieldwork practicum students should have the opportunity to gain an understanding and appreciation of the experience of individuals, groups and communities within a range of different fields of practice, settings, client groups and geographical locations.(IASSW, 2010, p 47) The field work in Australian social work addresses the fields like : Aboriginal and Torres Strait Islander cultures; mental health; child wellbeing and child safety; ageing; income security; health; disability; cultural and linguistic diversity; rural and remote locations; correctional services and justice; housing and homelessness; international practice and education.

\section{Challenges in Social Work Education}

The challenges that are related to the social work education and practice are discussed further relate to curriculum design; teaching of field practice, research and accreditation and registration.

In the Indian context curriculum is understood as 'the total learning experience provided by a school i.e. not just the content of courses (the syllabus), but also the methods employed (strategies), and values, norms, which relate to the way the social work school is organised. The present curriculum of the social work India appears to be requiring 
changes and updating of its contents to meet current day requirements (UGC second review committee report on Social work education 1975.p15). Social work curriculum in India remains rather westernized and seems to be missing the components of indigenised social work (Botcha (2012). Indian social work has not adequately modified western social work to meet local cultural contexts. The cultural diversity present in India to an extent and emerging diversity in Australia with newly settling communities seems to be posing challenges to curriculum development. Students in India have to reflect on caste and class to a large extent and the students of social work in Australia reflect on diversity in ethnicity, race, class, sexuality and age. Attention to diversity and cross cultural training is mandated by the Australian Association of Social Workers as requirements for social work education. However there is little empirical evidence that suggests progress made by individual schools of social work interpreting diversity and incorporating it into their programs.

The next issue that this paper addresses is about field practice. Fieldwork in the present Indian social work education is facing many challenges and requires addressing. Absence of a common fieldwork manual for students of social work across the country is very much felt. The decision making authorities in the university administration do not adequately appreciate the uniqueness of the social work field practicum, hence, the support from them is limited. Compounding this is lack of trained staff in agencies that can offer social work supervision in many places in the country and also inadequacy of social work practice agencies. Some regions in the country continue to face an acute need for fieldwork placement agencies. Establishing the minimum standards for fieldwork in terms of the numbers of hours, quality of supervision, placement of students in agencies and communities is also a serious issue which need to be addressed in the present context to enhance and establish a more relevant and reformed social work practicum. In Australia, fieldwork placement of social and community work students is dependent on the voluntary good will of the managers of social service agencies to support and resource it. Social work educators and students have always recognised and valued fieldwork placement as an essential component in the social work curriculum and students relish the challenge. The contribution of fieldwork placement is prized for its role in developing student skills, knowledge, and competencies as they learn to integrate classroom learning with the realities of agency practice. Social work educators would hope that the student completes placement feeling inspired to be the very best social workers they can be in the future. Fieldwork placement has been described by Doel and Shardlow (1996) [cited in J Dhemba (2012) as the 'heartbeat of social work'. On the other hand, looking at the challenge Dearsley (2000) comments that graduates in Australian society were not well prepared for child protection work and that their training on child abuse was minimal. In addition, Napan (1997) reported that there was a dislike for the idea of students practicing on clients because their lack of experience and those with an inquisitive nature might add to clients' burdens, which suggests that students must be advanced in their study prior to placement. There is also a lack of crosslearning and sharing between different schools of social work in both the countries. In India many schools of social work across the country offer an elective course in social work degree but the elective courses do not adequately prepare the student towards a specificity of work or practice such as geriatrics. The assessments of written examination of students being assessed by the non- social work educators in some regions of the country, also affects the quality of the social work education. The non-availability of textbooks in Indian language is another major challenge for appropriate production of knowledge, without which it is difficult to develop a strong theoretical base for the profession. The paper will now move to another important area of social work research. While social work educators recognise this to be an area that is integral part of the teaching and the learning, once again there is limited encouragement and participation by the faculty themselves in research undertakings. It appears that a platform that interfaces action researchers, educators, and the students to share and discuss research findings is very much needed in both the countries. The divide between the three is much more felt in India widening the gap between the research and the teaching, learning practice. It is an irony that most of the research is becoming a subject to be shelved in the libraries of the respective institutions (Goswami, forthcoming) rather than applying the findings in the teaching and learning practices. Observations further unveil that no priorities are given for research in the contemporary issues of social work. Besides, in India, there is either no or very little funding for social work research when compared to the other fields. Until now, most of the schools of social work in India have failed to adopt the research as a compulsory component in the curriculum. Instead, the students are given the option to choose either research or the term papers as a component in their course, which is once again creating an obstacle in providing uniformity in the social work education. Hence, there is an urgent need to emphasise on research to develop social work education. In Australia, too due to human ethics clearances that consume a lot of time, undergraduate and MSW research appears to be simulated or restricted to reviews of literature.

However it is heartening to note Australia social work education and the Australian Association of Social Workers address the need for social work research in the AASW Policy and Procedures Manual (1998), that states: 'there should be clear connections between the academic and research pursuits of university staff members, and field education experiences offered by the school' (AASW, 1998, p. 9). This clear relationship will help the profession to share the experiences and ultimately in the development and the enhancement of the social work education, and the teaching practices in the country. The paper now addresses the issues 
concerning accreditation of the courses and also the registration processes of social workers who obtain a degree. Indian social work education is accredited by the University Grants Commission, and the National Accreditation and Assessment Council. The challenges with respect to the accreditation of social work degree are: maintaining the minimum standards in the accreditation process is becoming a challenging task for the Indian social work education because of the widespread diversity in the same across the country. In India, there is no system to license or register social work practice. Simultaneously the accreditation norms for the distance education courses and the challenges of meeting the requirements of social work seem to present another unique set of surmountable problems.

In Australia the social work industry association the AASW has developed Practice Standards to outline the expectations required of all social workers. They are designed to guide social workers' practice to ensure they fulfill AASW Code of Ethics (2010), the Code that provides the foundation for the practice standards. The values and ethical responsibilities as detailed in the Code underpin all practice and therefore, form the basis of the standards outlined in this document. The practice standards inform the Australian Social Work Education and Accreditation Standards (ASWEAS) which regulate and guide curriculum development for social work programs in Australia. Graduates from AASW accredited programs are eligible for membership of the AASW as per the AASW's Constitution and membership eligibility criteria.

Certainly unique to India is the challenge of norms regarding ideal teacher student ratio. In schools of social work this is highly skewed, especially in the private full fee charging institutions. The enterprise bargaining in India has turned teachers accepting lower salaries, long hours and inadequate professional development.

\section{Social Work Education in General}

Apart from the above, despite social work education's slant towards human rights, there are few who work in the human rights sector. The social activists in India emerge from all professional backgrounds and social work dependent on either government or international funding or local funding seems to struggle to work to its professed commitment. There is clearly some tension between social work and social activism. There is also a noticeable regional imbalance in the allocation of the schools of social work in the country. Some parts of India have none virtually and some areas have over 200. Besides, the curriculum is obsolete as it fails to focus on issues like human rights, Dalit and Tribal studies and para-legal education in the context of globalisation. In addition, the infrastructure and the facilities, which are very basic for the social work education, are also not available in many institutions. In spite of the development of social work as a branch of social science during the last seven decades, there is little or no partnership with the government and the non- governmental sectors. Further, the admission process must be streamlined to prevent the drop-out rates. Finally, the social work education is highly commercialised in India, that is, central aim of the institutions, and the schools of social work education developing and running social work degree is to make huge profits. Hence, controlling and regulating the activities of the private institutions such as the admission process, a cap on the maximum amount of fees that a particular private institute can charge, regulation on maintaining the minimum standards in the social work teaching, and practice remains a grave concern.

Future needs of social work: In order to enhance the quality of social work education in the country at the postgraduate level and to meet the professional challenges in the social work practice, there is an urgent need for addressing the challenges and the possibilities in the social work education. There is also a need for Indian social work education to learn and adopt from the social work practices around the world. The following are the major needs in the social work education.

1. A number of social work institutions need to be established in rural India to address the rural people's needs and to bridge the gap between rural and urban social work institutions. These institutions should aim to produce highly qualified social workers who can work in rural areas at the panchayat (the village level), taluka or at the block levels. In addition to this, there is a need to create professionally trained social workers, who can transform the welfare and the development programmes of the country into reality.

2. The institutions of social work suffer greatly from inadequate funds for research and development. Hence, there is a need for availability of greater funds, which would encourage not only innovative social work research but would bring together social work scholars from across the country to share ideas and innovations without compromising on quality. Online knowledge base must be developed to link up all the schools of social work and their respective resources.

3. A standard curriculum for social work education must be developed across the country, which will suit to the local context of different schools of social work.

4. The universities and the departments need to be strengthened and the lectures should be made available online so that the students with little or no opportunities would benefit from the knowledge base of experienced educators in the country.

5. It has already been stated above that the quality of social work education in many of the institutions is sub-standard both academically and administratively with skewed teacher-student ratios. Majority of the institutions are private institutions, and are self-financed and bear exorbitant fee structures. Sadly, some schools of social work also promote the concept 
of paid seats and many a times charge capitation fee from the students. The fieldwork training component in these institutions is weak. Hence, I reiterate that the fee-structure of these institutions needs to be controlled and the strict accreditation rules has to be followed during the accreditation process. Those institutions that fail to respect the ideology of social work education must not be granted accredit ion.

6. There is a tremendous growth in the distance education sector because of high fee structures of the self-financed institutions for the regular social work courses. Many students consider distance education as the most economical and best option of receiving a postgraduate degree in social work. This trend is effecting the standards of social work profession as the distance education do not provide the good quality of practical experience to the candidates and the fieldwork component remain absent in most cases, which in turn. affects the quality of social work education and therefore, this process should be discouraged as far as social work education is considered.

7. The personnel management and industrial relations provided in many schools of social work as an area of specialisation has slowly shifted its focus from labour issues and has moved away from the ideology of social work. Hence, there is an urgent need to look at delinking this specialisation from social work education and if necessary, there must be an initiation to start separate post-graduate programmes in human resource management.

8. There is a need to establish a National Council for Social Work Profession under the Ministry of Social Justice and Empowerment or Ministry of Human Resource Development so that the licensing of social work practice may be effectively introduced, which will help to enhance the social work standards.

9. The social work education must go beyond the limited pre-existing framework of social work in the local context. For this, the generic programmes in social work must be removed and new specialisation sought to be introduced which are more appropriate to the different socio-cultural contexts with special focus on rural social issues. I restate here that for this reason there is a need to establish new schools of social work in the rural areas.

10. Until now, some of the schools of social work in the northern region of the country are functioning within the university system as departments of social work, whereas few of them functions as a part of social sciences/sociology departments. Hence, there is a need to separate the social work departments from the other departments and to start individual schools of social works within the university system to enjoy greater flexibility and development.

11. There is an extreme variation in the social work curriculum in different schools of north India. In addition, most of the social work curricula are highly influenced by the market economy and the availability of jobs. In the northern region of the country, most of these schools are located in the urban areas and therefore, the students fail to enjoy rural exposure.

12. There is a greater need for achieving certain uniformity in social work curriculum including the fieldwork component and the practice and training. Certain minimum standards need to be established in fieldwork in terms of the number of hours, quality of supervision, and the placements of students in different agencies and communities. Besides, the university authorities 'views all the departments with the same lens and thereby, are unable to find the uniqueness of the social work course and the special needs of the social work degree programme. Hence, there is a need to set a national body for the social work education in the country.

13. The social work research as an area needs more attention in social work education in order to develop a sound theoretical base for the profession. The research needs to be strengthened with adequate infrastructure and teaching facility, which would help professional practitioners develop a grounded theory building in the profession for the development of the discipline.

Further, the UGC review committee on social work education highlights the following areas as a concern for the development of social work education in India. It needs to ensure a systematic development of social work education in terms of its geographical distribution and affiliation to recognised boards of education and universities along with providing a holistic framework for the development of a ladder education programme with several termination points related to job functions in the country, and to relate each phase education to the next, so that there are no dead-end training programmes and no dead-end jobs which will result in the enhancement of the standard of the social work profession and the practice. UGC also emphasises that there is a great need to develop curriculum, which are under constant review for relevance and which provide a career ladder from one academic level to the next. The fieldwork and field service projects need to be developed in the schools of social work. The professionals in the social work and the institutional stakeholders in the country should show interest for publishing books and case studies related to social work/social welfare/social development for all academic levels from the para-professional upwards. Well-developed teaching materials at all academic levels need to be created with the support and the participation of the subject expertise and the consultants.

A recent report on social welfare education in Australia highlighted the lack of attention by Australian social work education such as:

1. Australian social work education is highly influenced by the American and the British models, the theories of social works are heavily borrowed from American 
and the British social work, and hence, it is not correctly suitable to the diverse problems of the Australian society. There is a greater need for the Australian social work to develop the indigenous social work method developed on the basis of its own culture and tradition.

2. The social work education in Australia needs to address the problems of migrants, since Australian immigration programme has a modern trend. The social work education needs to look at the analysis, solutions and the policy development for the migrant problems.

3. There is a great need for social work to look at the situation of the Australian aboriginals.

4. The social work need to be established in the rural parts of the Australian society. The rural areas of Australia remain completely isolated because of the settlement pattern of the Australian population. In order to address the regional imbalance and to address the needs of rural people, the social work approach in rural area is an urgent requirement.

5. Need for developing the industrial social work has been felt. The social work in Australia has not yet dealt with the issue of union versus management affiliation in industrial settings. There is a scope for the industrial social work practice in the present society.

6. Urgency is also felt in the social work community in Australia to establish structures for closer dialogue amongst schools of social work, the professional association, and the employers in order to strengthen and re-develop the practice and the training.

7. There is a need for the educators of social work to establish a collective voice and promote the values, which should desirably underpin tertiary education in Australia.

\section{Conclusion}

In this paper, we have examined the development of social work in India and in Australia, the course content, the qualification, the challenges and the opportunities for the social work education in both the countries. Both in India and in Australia, the social work curriculum need to be indigenised as it is highly westernised to date. The problems like the inadequate funds for the social work research, diversity in the regions, extreme variation in the curriculum and the fieldwork practicum, mushrooming of the private social work institutions which is resulting in the commercialisation of the social work education, extreme skewedness in the teacher-student ratio in some regions of the country need to be focused in the social work education in the Indian society. While the Australian social work too has been influenced by westernisation and the content of the social work and the curriculum are directly taken from the western social work, Australian social work till date follows the American model and the British model of social work education, and the teachers in many institutions are originally not an Australian citizen and are mostly either from Britain or from America. As the curriculum of the study and the training that students receive including, courses that are taught in the discipline are determined by the professors and the teaching staffs of the universities and the schools of social work, therefore, the social work fraternity in Australia need to look at training its own graduate to take up the profession in the country. With respect to the curriculum of the social work, it is rather difficult to generalise about the curriculum design since it varies from university to university. Most of the social work programmes, has the components similar to that of the American schools of social work. Hence, the social work in Australia need to re-develop a system, which is more relevant to the local context.

India need to focus in the field of accreditation of the social work degree as the country is facing difficulties to control the mushrooming of the schools of social work across the country. Perhaps, India can revisit the Australian model of accreditation.

Public sector is the major employment provider for the social workers in Australia. This is because; the public sector adheres to the norms of high quality social work practice by following strict regulations and the guidelines from the AASW. Indian social work need to chalk out the opportunities for the social workers in the different fields, which will help the social work profession to grab an identity. There is also a need to develop the social work education and the profession, which will fit into the local socio-economic and the political context of the country rather than being influenced by the ideology of the western social work and following as it is. Nevertheless, the flow of professionals and the ideas from all over the world would be a contributing factor when it is considered as a base for developing the social work education which is rooted in the needs and culture of its own society.

\section{REFERENCES}

2013: Report of Consultation on social work education, North East Zone, TISS Guwahati.

2013: Report of national Network of schools of social work for quality enhancement of social work education in Indi, TISS, Mumbai.

Andrea Tamburro (2013), Including Decolonilization in Social work education and practice, journal of Indigenous social Development, volume 2, Issue 1, 2013.

Australian social work education and Accreditation standers (2008), Australian Association of Social workers.

Australian social work education and Accreditation standers (2009),Australian Association of Social workers. 
Australian social work education and Accreditation standers (2010),Australian Association of Social workers.

Australian social work education and Accreditation standers (2012),Australian Association of Social workers.

Carolyn Noble and Mark Hendrickson (2011), Social work field educationand supervision across Asia Pacific, Sydney University presses University of Sydney.

Dr. Alana Thompson (2011), Social work education Project; Curriculum mapping for content on forgotten Australians.

Goswami, Indrajit (forthcoming).Critical Observation on Methodologies of Select Doctoral Research Studies, Space and Culture, India Special Methodology Edition Plus Miscellaneous

Green R. (2005), Challenges for social work and social welfare education in the 21st century: a contextual analysis, in higher education in a changing world, proceedings of the 28th HERDSA Annual conference, Sydney 3-6. July 2005: pp 150.

Jill Gibbons \& Mel Gray (2002), an integrated and experience base and approach to social work education; the Newcastle model of social work education, Vol. 21, No.5, 2002.

Jill Wilson (2005), an overview of social work education in Australia, Partularia Vol.1.2005. [187-2013].

Linda, Rosenmen (1980), Social work education in Australia the impact of the American Model, Journal of Education for social work, Vol.16, No. 1, winter 1980, PP-112-118.

Lindsey Napier\& Janet George (2001), changing social work education in Australia, social work education, Vol.20, No1, 2001.

Mel Gray (2011) the changing faces of social welfare and social work in Australia ERIS web Journal 2/2011.

Mel Gray, Jan fook (2004), the quest for a Universal social work: some issues and implications, social work education vol. 23, No.5,
October 2004, pp625-644.

Mel Gray, Jill Gibbons (2004), Critical thinking as Integral to social work Practice, Journal of teaching in social work, Vol.24(1/2) 2004.

Mel Gray, Kylie Agllias (2013), international social work and social welfare; Australia and pacific Islands, Encyclopedia of social work.

NAAC (2004) A manual for assessment and Accreditation of social work education programme, New Delhi.

Peter Camilleri (2005) Social work education in Australia; at cross roads, Partularia. Volume V, Issue 2005, PP. 171-184.

Peter Camilleri (2005), Social work education in Australia at the cross roads, Portularia, Vol.V, No. 1, 2005.

Peter Camilleri\& Martin Ryan (2007), advances in social work and welfare education, journal of the Australian association for social work and welfare education, Volume 9, November 2007.

Practice standards for school social workers; Achieving out comes (2008), Australian Association of Social workers.

Prof. Vimla V Nadkarni, Kaivalya Desai(2012), A report on national consultation on national network of schools of social work for quality enhancement of social work education in India, Tata Institute of Social Sciences, Mumbai, 2012.

Ramababu Botcha (2012), Problems and Challenges for social work education in India: some recommendations, International Journal of Multidisciplinary educational research. Volume.1, Issue3, Aug 2012.

Tom Puckett, Andrew Jones (1979), Social work education in Australia: the late 1970s, Canadian journal of social work education, vol.5, No 2/3. 1979, pp 48-75.

University Grant Commission (2001) UGC Model Curriculum on social work education, New Delhi. 